\title{
Transient cerebral ischemia in an elderly patient with patent foramen ovale and atrial septal aneurysm
}

\author{
Alfonso Merante' \\ Pietro Gareri \\ Alberto Castagna ${ }^{2}$ \\ Norma Maria Marigliano 3 \\ Mafalda Candigliota ${ }^{4}$ \\ Alessandro Ferraro ${ }^{4}$ \\ Giovanni Ruotolo' \\ 'Geriatric Unit, "Pugliese-Ciaccio" \\ Hospital, ${ }^{2}$ Azienda Sanitaria \\ Provinciale (ASP), Catanzaro, ${ }^{3}$ SERT \\ Taranto, ASL Taranto, ${ }^{4}$ Intensive \\ Cardiology Unit, "Pugliese-Ciaccio" \\ Hospital, Catanzaro, Italy
}

This article was published in the following Dove Press journal:

Clinical Interventions in Aging

7 September 2015

Number of times this article has been viewed

\begin{abstract}
Cerebrovascular disease is one of the most common causes of cerebrovascular morbidity and mortality in developed countries; up to $40 \%$ of acute ischemic strokes in young adults are cryptogenic in nature - that is, no cause is determined. However, in more than half of these patients, patent foramen ovale (PFO) is seen along with an increased incidence of atrial septal aneurysm (ASA). The following is a report of an interesting case: a 68-year-old man with ASA and transient cerebral ischemia. Transesophageal echocardiography (TEE) showed the presence of ASA; a test with microbubbles derived from a mixture of air and saline or colloids pointed out a shunt on the foramen ovale following Valsalva's maneuver. The patient underwent percutaneous transcatheter closure of the interatrial communication by an interventional cardiologist. TEE and transcranial Doppler or TEE with the microbubbles test are the recommended methods for detecting and quantifying intracardiac shunts, both at rest and following Valsalva's maneuver. In patients following the first event of transient ischemic attack, and without clinical and anatomical risk factors (such as the presence of ASA, PFO, and basal shunt), pharmacological treatment with antiplatelets or anticoagulants is closely recommended. On the contrary, in patients following the first event of transient ischemic attack, or a recurrent event during antiplatelet treatment, the percutaneous closure of PFO is recommended.
\end{abstract}

Keywords: atrial septal aneurysm, patent foramen ovale, elderly, transient cerebral ischemia, percutaneous closure

\section{Introduction}

Cerebrovascular disease is one of the most common causes of cerebrovascular morbidity and mortality in developed countries; in fact 12-20/1,000 people/year between the ages of 75 and 84 years will experience a stroke. ${ }^{1}$ In $40 \%$ of cases, no trigger is present ${ }^{2}$ (cryptogenic forms where neither coagulation alterations nor embolic sources are present), but interatrial defects such as patent foramen ovale (PFO) are seen in more than half of these patients. PFO is also seen along with an increased incidence of atrial septum aneurysm (ASA). ${ }^{3}$ Foramen ovale is formed at approximately the fifth week of gestation, during the process of segmentation of the primary atrial cavity.

The separation between the two atria occurs following the primary septum descent toward the atrioventricular plane. At first, the communication is maintained through the ostium primum placed at the lowest part of the septum and is closed when the primary septum merges with the endocardial cushions.

Ostium secundum derives from the reabsorption of the septum; the foramen is closed by the secondary interatrial septum, which is formed from the upper wall of the right atrium. Septum primum and septum secundum overlap; the deriving channel
Correspondence: Pietro Gareri ASP Catanzaro, DSS2 Catanzaro Lido, Poliambulatorio viale Crotone 88I00, Catanzaro, Italy

Tel +390961731219

Fax +390961 731 031

Email pietro.gareri@alice.it 
formed by the two septa (foramen ovale) allows the blood coming from the uterine veins to enter directly into the left atrium, bypassing the pulmonary circulation. After birth and within the first year of life, the different pressure levels of the two atria (superior in the left atrium) cause the fusion of the two septa, with the closure of the foramen ovale and right-left shunt termination. ${ }^{4}$ However, in about $25 \%$ of the adult population, the foramen continues to remain patent. ${ }^{4-6}$ The prevalence of PFO in the general population tends to decrease with increasing age, from $34 \%$ in the first three decades, up to $20 \%$ in the ninth decade. ${ }^{7,8}$ Spontaneous closure even late in life, or selective mortality (reduced life expectancy of PFO carriers), have to be accountable., ${ }^{4,8}$ The ASA is an eversion of the septum that may be globally interested, or as occurs more frequently in correspondence with the region of the oval fossa. ${ }^{9}$ Hanley et a ${ }^{10}$ was the first to define the diagnostic criteria, identifying ASA as a protrusion of the atrial septum or a phasic excursion during the same cardiorespiratory cycle, with a total amplitude superior to $15 \mathrm{~mm}$ and a base diameter superior to $15 \mathrm{~mm}$.

These parameters have been modified by other researchers who believe that a diagnosis of ASA is justified when protrusion inside one of the two atria is superior to $10 \mathrm{~mm}$, or a total range superior to $10 \mathrm{~mm}$ in the presence of an extension baseline $\geq 15 \mathrm{~mm}^{11}$

The prevalence of ASA is variable in relation to the cut-off number used, the detection method used, and the population studied. When it is studied by transthoracic echocardiography (TTE) in a healthy population, the prevalence is $0.08 \%-1.2 \%,{ }^{12}$ whereas by transesophageal echocardiography (TEE), it rises up to 2\%-10\%. ${ }^{11,13}$ According to Overell et al's ${ }^{14}$ meta-analysis, the prevalence of ASA is $2 \%-17 \%$ in stroke (from all causes), $4 \%-25 \%$ in cryptogenic stroke, $0.2 \%-22 \%$ in stroke from unknown causes, and $0 \%-15 \%$ in the control population. In a recent study, the relationship between $\mathrm{PFO}$ and cryptogenic stroke was pointed out in patients over the age of 55 years as well. ${ }^{15}$

In the present paper, we report an interesting case of a 68-year-old man with ASA and transient cerebral ischemia.

\section{Case report}

A 68-year-old man was visited due to episodes of dizziness and postural instability that he had been experiencing for 2 months.

The patient was affected with hypertension; in 2005 and in 2007, he was hospitalized in an internal medicine ward for lone atrial fibrillation and in 2008 in a neurological ward for stroke with left hemiparesis. No further crises of atrial fibrillation were demonstrated on repeated Holter electrocardiography (ECG) monitoring. He was also affected with benign prostatic hypertrophy.

He was taking ticlopidine $250 \mathrm{mg}$ twice a day, esomeprazole $20 \mathrm{mg} /$ day, valsartan $80 \mathrm{mg} /$ day, and tamsulosin $0.4 \mathrm{mg} /$ day. Clinical examination showed that he was oriented, with mild hyposthenia in the left limbs. Cardiac activity was rhythmic at 70 beats/minute, and the arterial pressure was 140/75 mmHg.

The vesicular murmur was present, but it was sour; the abdomen was treatable, and the liver was palpated at $1 \mathrm{~cm}$ from the arch rib. Hemochrome, renal and hepatic functions, thyroid hormones, coagulation, and thrombophilia screening were normal.

Brain computed tomography (CT) scan showed vascular lesions with a hypodense malacica area in the right occipital lobe. Supra-aortic Doppler ultrasound showed carotid atheromasia without any significant hemodynamic changes.

Holter ECG reported sinus rhythm, extrasystoles, and episodes of supraventricular bigeminism. Cardiac function was investigated through TTE, which showed mitroaortic fibrosis and mild mitral insufficiency. A pulmonary arterial pressure of $43 \mathrm{mmHg}$ and atrial septum abnormal excursion during the cardiorespiratory cycle were also found.

TEE showed the presence of ASA; a test with microbubbles, derived from a mixture of air and saline or colloids, revealed a shunt on the foramen ovale, following Valsalva's maneuver.

The case was assessed again with the aid of the interventional cardiologist. The patient underwent percutaneous transcatheter closure of the interatrial communication by an Amplatzer $40 \mathrm{~mm}$ device. The use of this device was due to the presence of a big cribrate aneurysm.

The procedure was performed under general anesthesia, with the patient in endotracheal intubation, monitored by TEE after cannulation of the femoral vein, using the Seldinger technique.

The occluder device was inserted using two disks of nitinol and an intermediate bridge (waist) with a link function and a stent; it was screwed to a solid wire and was released after the adhesion of the two disks to the defect borders. Doppler ultrasound assessed the absence of a residual shunt.

The patient was discharged after 4 days; antiplatelet therapy with ASA $100 \mathrm{mg} /$ day and clopidogrel $75 \mathrm{mg} /$ day, as well as a pattern of antibiotic prophylaxis for bacterial endocarditis, was suggested. 


\section{Discussion}

TEE and transcranial Doppler, or TEE with the microbubbles test, are the suggested methods for detecting and quantifying intracardiac shunts, both at rest and following Valsalva's maneuver. ${ }^{16-18}$ TEE is an irreplaceable examination for characterizing the interatrial septum and the aortic root. ${ }^{19}$

It is also fundamental for measuring all the required parameters necessary for carefully scheduling the intervention of percutaneous closure. ${ }^{20}$ Table 1 reports all the parameters to check on TEE.

Recently, the Randomized Evaluation of recurrent Stroke comparing PFO closure to Established Current standard of care Treatment (RESPECT) study ${ }^{21}$ suggested that patients affected with ASA and presenting with a significant right-to-left shunt are at the highest risk of stroke. There was no significant benefit associated with closure of a PFO in adults who had had a cryptogenic ischemic stroke. However, closure was superior to medical therapy alone in the prespecified per-protocol and as-treated analyses, with a low rate of associated risks. ${ }^{21}$ Conversely, in the Patent Foramen Ovale and Cryptogenic Embolism (PC) trial, ${ }^{22}$ closure of a PFO for secondary prevention of cryptogenic embolism did not result in a significant reduction in the risk of recurrent embolic events or death, as compared with medical therapy.

Before these studies, CLOSURE ${ }^{23}$ (the first randomized study) did not show any significant changes in the study endpoints among patients treated with drugs and those who underwent PFO closure by the Starflex device (NMT Medical, Inc., Boston, MA, USA). However, since the latter device does not have good clinical quality, it was no longer marketed. CLOSURE I was extremely criticized for the clinical difference in inclusion criteria, the low number of patients enrolled, and the device used. ${ }^{23}$ On the contrary, the RESPECT study trial ${ }^{21}$ showed the advantages of the catheter-based device closure through the use of a safer and

Table I Parameters to check on TEE

I. Atrial septum length and thickness

2. PFO tunnel length and amplitude

3. Presence/absence and measurement of septal aneurysm (basis excursion and amplitude)

4. Measurement of anterior-superior rim (minimum distance of the beginning of the tunnel from the atrial anterior-superior wall)

5. Presence/absence of atrial multifenestrated septum

6. Eustachian valve measurement

7. Presence/absence of Chiari network

8. Quantitative measurement of shunt by microbubbles (significant shunt for transition of $>20$ bubbles)

Abbreviations: TEE, transesophageal echocardiography; PFO, patent foramen ovale. more effective device, such as the Amplatzer, and of more accurate inclusion criteria.

In patients following first event of transient ischemic attack (TIA), and without clinical risk factors (such as conditions that may facilitate deep venous thrombosis) and anatomical risk factors (such as the presence of ASA, an amplitude of PFO $>4 \mathrm{~mm}$, and a basal shunt), pharmacological treatment with antiplatelets or anticoagulants is highly recommended. If catheter-based device closure is contraindicated, or if the patient refuses the procedure, the treatment of choice is medical through oral anticoagulation. On the contrary, in patients following the first event of TIA or a recurrent event during antiplatelet treatment, the percutaneous closure of PFO is recommended. ${ }^{20,24}$ Interventional treatment, when indicated, should be postponed to at least 1 month after the stroke; furthermore, heparin necessary during the procedure could be dangerous in big-sized brain lesions. In people affected with minor stroke or TIA, no latency time is requested before the procedure. ${ }^{20}$

The first experience of the percutaneous closure of an atrial septal defect occurred in 1976 with a 23 French delivery system. ${ }^{25}$ The devices currently available make the process extremely easy and there are very few risks, with a mortality rate much less than $1 \%{ }^{26}$

The risks are related to anesthesia and to possible embolization of the device. ${ }^{27}$ However, this event is very rare based on the safety of the screw delivery system; there is also the possibility that the Amplatzer system can be reinserted in the interposer if it is not properly placed. ${ }^{5}$ When ASA is present, the procedure of percutaneous closure of the PFO can be considered as the secondary prevention of cryptogenic stroke, even in elderly patients.

In fact, Overell et al' $\mathrm{s}^{14}$ meta-analysis aim was to examine the association between PFO, ASA, and stroke. Data from case-control studies that examined the relative frequency of PFO, ASA, or both in all patients with ischemic stroke, cryptogenic stroke, and known stroke etiology, as well as in control subjects, were included. Combined odds ratio (OR) were calculated using the fixed-effects (FE) and random-effects (RE) methods. Homogeneous results were found within the group younger than 55 years old: using $\mathrm{FE}, \mathrm{OR}=3.10(95 \%$ confidence interval [CI]: 2.29-4.21) for $\mathrm{PFO}$; OR=6.14 (95\% CI: 2.47-15.22) for ASA; and $\mathrm{OR}=15.59$ (95\% CI: 2.83-85.87) for PFO plus ASA. For patients older than 55 years old, using FE, OR=1.27 (95\% CI: 0.80-2.01) for PFO; OR=3.43 (95\% CI: 1.89-6.22) for ASA; and OR=5.09 (95\% CI: 1.25-20.74) for PFO plus ASA. Therefore, PFO and ASA are significantly associated 
with ischemic stroke in patients younger than 55 years old. Further studies are needed to establish whether the association between PFO and ischemic stroke may exist in patients older than 55 years of age. ${ }^{28}$

The importance of the combination of defects in the determinism of cryptogenic forms of acute cerebrovascular ischemia is also supported by other authors. ${ }^{29}$ The postulated pathogenetic mechanism is primarily due to paradoxical embolism - that is, transition of the left atrium of a thrombus from the venous side, with subsequent embolization. This hypothesis was postulated for the first time in 1877 by Cohnheim ${ }^{30}$ after performing an autopsy on a young woman affected with PFO who died of a stroke. In most cases, the embolic source remains undetermined; in fact, deep venous thrombosis is found only in $5 \%-10 \%$ of cases. ${ }^{31}$ Only in a few cases is it possible to identify overt risk factors for thromboembolism such as trauma, oral contraceptives, or hypercoagulable states. ${ }^{32}$ Therefore, it was hypothesized that the thrombus formation can take place in situ, just in the PFO (it is morphologically similar to a tunnel), or on the surface of the aneurysm, especially if fixed, given the occurrence of the phenomena of blood stasis inside it. ${ }^{33}$

In this regard some evidence has reported that the surface of the ASA may be cribriform with the loss of substance and the consequent increase in the thrombotic risk. ${ }^{34,35}$ The arrhythmic hypothesis is another possibility: Berthet et $\mathrm{al}^{3}$ have demonstrated atrial vulnerability in $60 \%$ of patients with ASA plus PFO. ${ }^{3}$ This could be related to local septal stretching with electrophysiological changes, which could be the cause of paroxysmal atrial fibrillation. ${ }^{3,36}$

Finally, it is worth noting the possible association between ASA and persistent Eustachian valve, which positively correlates with the risk of paradoxical embolism. This might perhaps be related to the directing of blood flow to the oval fossa, thus leading to a facilitation of the right-to-left shunt. ${ }^{12}$

\section{Conclusion}

After the interventional treatment, TTE is highly recommended before discharge at 1 month, 3 months, 6 months, and 12 months, and at each year thereafter. TTE with microbubbles is requested after 6 months, and a Holter ECG needs to be performed when requested from the clinical picture. TEE is requested if TTE shows a significant right-to-left shunt, or in any case when suggested based on the clinical picture.

\section{Acknowledgments}

We should thank Miss Leane Gigliotti and Miss Annamaria Squillace for their kind support in English language revision.

\section{Disclosure}

The authors report no conflicts of interest in this work.

\section{References}

1. Feigin VL, Lawes CM, Bennett DA, Anderson CS. Stroke epidemiology: a review of population-based studies of incidence, prevalence, and casefatality in the late 20th century. Lancet Neurol. 2003;2(1):43-53.

2. Sacco RL, Ellenberg JH, Mohr JP, et al. Infarcts of undetermined cause: the NINCDS Stroke Data Bank. Ann Neurol. 1989;25(4):382-390.

3. Berthet K, Lavergne T, Cohen A, et al. Significant association of atrial vulnerability with atrial septal abnormalities in young patients with ischemic stroke of unknown cause. Stroke. 2000;31(2):398-403.

4. Presbitero P, Aldrovandi A, Pagnotta P, Zavalloni D, Lisignoli V, Milone F. Forame ovale pervio: innocente o colpevole? Ipotesi, evidenze e risultati della sua chiusura percutanea nelle sindromi cliniche in cui è implicato. Cardiology Science. 2006;4:217-225. Italian.

5. Papa M. Indicazioni e tecnica della chiusura percutanea dei difetti del setto interatriale. Emodinamica. 2003;34:9-14. Italian.

6. Penny DJ, Vick GW 3rd. Ventricular septal defect. Lancet. 2011; 377(9771):1103-1112.

7. Hagen PT, Scholz DG, Edwards WD. Incidence and size of patent foramen ovale during the first 10 decades of life: an autopsy study of 965 normal hearts. Mayo Clin Proc. 1984;59(1):17-20.

8. Meier B, Frank B, Wahl A, Diener HC. Secondary stroke prevention: patent foramen ovale, aortic plaque, and carotid stenosis. Eur Heart J. 2012;33(6):705-713, 713a, 713b.

9. Serafini O, Misuraca G, Greco F, Bisignani G, Manes MT, Venneri N. [Prevalence of structural abnormalities of the atrial septum and their association with recent ischemic stroke or transient ischemic attack: echocardiographic evaluation in 18631 patients]. Ital Heart J Suppl. 2003;4(1): 39-45. Italian

10. Hanley PC, Tajik AJ, Hynes JK, et al. Diagnosis and classification of atrial septal aneurysm by two-dimensional echocardiography: report of 80 consecutive cases. J Am Coll Cardiol. 1985;6(6):1370-1382.

11. Pearson AC, Nagelhout D, Castello R, Gomez CR, Labovitz AJ. Atrial septal aneurysm and stroke: a transesophageal echocardiographic study. J Am Coll Cardiol. 1991;18(5):1223-1229.

12. Carerj S, Zito C, Oliva S, et al. [Atrial septal aneurysm: a true embolic source?]. Ital Heart J Suppl. 2005;6(3):135-144. Italian.

13. Marazanof M, Roudaut R, Cohen A, et al. Atrial septal aneurysm. Morphological characteristics in a large population: pathological associations. A French multicenter study on 259 patients investigated by transoesophageal echocardiography. Int $J$ Cardiol. 1995;52(1): $59-65$.

14. Overell JR, Bone I, Lees KR. Interatrial septal abnormalities and stroke: a meta-analysis of case-control studies. Neurology. 2000;55(8): $1172-1179$.

15. Handke M, Harloff A, Olschewski M, Hetzel A, Geibel A. Patent foramen ovale and cryptogenic stroke in older patients. $N$ Engl J Med. 2007; 357(22):2262-2268.

16. González-Alujas T, Evangelista A, Santamarina E, et al. Diagnosis and quantification of patent foramen ovale. Which is the reference technique? Simultaneous study with transcranial Doppler, transthoracic and transesophageal echocardiography. Rev Esp Cardiol. 2011;64(2): 133-139.

17. Maffè S, Dellavesa P, Zenone F, et al. Transthoracic second harmonic two- and three-dimensional echocardiography for detection of patent foramen ovale. Eur J Echocardiogr. 2010;11(1):57-63.

18. Pepi M, Evangelista A, Nihoyannopoulos P, et al; European Association of Echocardiography. Recommendations for echocardiography use in the diagnosis and management of cardiac sources of embolism: European Association of Echocardiography (EAE) (a registered branch of the ESC). Eur J Echocardiogr. 2010;11(6):461-476.

19. Mügge A, Daniel WG, Angermann C, et al. Atrial septal aneurysm in adult patients. A multicenter study using transthoracic and transesophageal echocardiography. Circulation. 1995;91(11):2785-2792. 
20. Pristipino C, Anzola GP, Ballerini L, et al; Italian Society of Invasive Cardiology (SICI-GISE); Italian Stroke Association (ISA-AIS); Italian Association of Hospital Neurologists, Neuroradiologists, Neurosurgeons (SNO); Congenital Heart Disease Study Group of Italian Society Of Cardiology; Italian Association Of Hospital Cardiologists (ANMCO); Italian Society Of Pediatric Cardiology (SICP); Italian Society of Cardiovascular Echography (SIEC); Italian Society of Hemostasis and Thrombosis (SISET). Management of patients with patent foramen ovale and cryptogenic stroke: a collaborative, multidisciplinary, position paper: executive summary. Catheter Cardiovasc Interv. 2013;82(1):122-129.

21. Carroll JD, Saver JL, Thaler DE, et al; RESPECT Investigators. Closure of patent foramen ovale versus medical therapy after cryptogenic stroke. N Engl J Med. 2013;368(12):1092-1100.

22. Meier B, Kalesan B, Mattle HP, et al; PC Trial Investigators. Percutaneous closure of patent foramen ovale in cryptogenic embolism. NEngl J Med. 2013;368(12):1083-1091.

23. Furlan AJ, Reisman M, Massaro J, et al. Closure or medical therapy for cryptogenic stroke with patent foramen ovale. N Engl J Med. 2012;366: 991-999.

24. Sacco RL, Adams R, Albers G, et al; American Heart Association; American Stroke Association Council on Stroke; Council on Cardiovascular Radiology and Intervention; American Academy of Neurology. Guidelines for prevention of stroke in patients with ischemic stroke or transient ischemic attack: a statement for healthcare professionals from the American Heart Association/American Stroke Association Council on Stroke: co-sponsored by the Council on Cardiovascular Radiology and Intervention: the American Academy of Neurology affirms the value of this guideline. Stroke. 2006;37(2):577-617.

25. King TD, Thompson SL, Steiner C, Mills NL. Secundum atrial septal defect. Nonoperative closure during cardiac catheterization. JAMA. 1976; 235(23):2506-2509.

26. Berdat PA, Chatterjee T, Pfammatter JP, Windecker S, Meier B, Carrel T. Surgical management of complications after transcatheter closure of an atrial septal defect or patent foramen ovale. J Thorac Cardiovasc Surg. 2000;120(6):1034-1039.
27. Chessa M, Carminati M, Butera G, et al. Early and late complications associated with transcatheter occlusion of secundum atrial septal defect. J Am Coll Cardiol. 2002;39(6):1061-1065.

28. Cujec B, Mainra R, Johnson DH. Prevention of recurrent cerebral ischemic events in patients with patent foramen ovale and cryptogenic strokes or transient ischemic attacks. Can J Cardiol. 1999;15(1): 57-64.

29. Mas JL, Arquizan C, Lamy C, et al; Patent Foramen Ovale and Atrial Septal Aneurysm Study Group. Recurrent cerebrovascular events associated with patent foramen ovale, atrial septal aneurysm, or both. N Engl J Med. 2001;345(24):1740-1746.

30. Cohnheim J. Thrombose und embolie. In: Vorlesungen über allgemeine Pathologie: ein Handbruch füur Aerzte und Studierende. Berlin, Germany: Hirschwald; 1877:134. German.

31. Gaspardone A, Iani C, Papa M. [Percutaneous closure of patent foramen ovale: a wise approach]. G Ital Cardiol (Rome). 2008;9(9):593-602.

32. Lethen H, Flachskampf FA, Schneider R, et al. Frequency of deep vein thrombosis in patients with patent foramen ovale and ischemic stroke or transient ischemic attack. Am J Cardiol. 1997;80(8):1066-1069.

33. Schneider B, Hanrath P, Vogel P, Meinertz T. Improved morphologic characterization of atrial septal aneurysm by transesophageal echocardiography: relation to cerebrovascular events. J Am Coll Cardiol. 1990;16(4): 1000-1009.

34. Silver MD, Dorsey JS. Aneurysms of the septum primum in adults. Arch Pathol Lab Med. 1978;102(2):62-65.

35. Attuel P, Rancurel G, Delgatte B, et al. Importance of atrial electrophysiology in the work-up of cerebral ischemic attacks. Pacing Clin Electrophysiol. 1986;9(6 Pt 2):1121-1126.

36. Ravelli F, Allessie M. Effects of atrial dilatation on refractory period and vulnerability to atrial fibrillation in the isolated Langendorff-perfused rabbit heart. Circulation. 1997;96(5):1686-1695.
Clinical Interventions in Aging

\section{Publish your work in this journal}

Clinical Interventions in Aging is an international, peer-reviewed journal focusing on evidence-based reports on the value or lack thereof of treatments intended to prevent or delay the onset of maladaptive correlates of aging in human beings. This journal is indexed on PubMed Central, MedLine,

\section{Dovepress}

CAS, Scopus and the Elsevier Bibliographic databases. The manuscript management system is completely online and includes a very quick and fair peer-review system, which is all easy to use. Visit http://www.dovepress. com/testimonials.php to read real quotes from published authors. 